\title{
Herbicidal Effects of Fungicides on Arable Weeds
}

\author{
Henning Nordmeyer, Tobias Koch
}

Julius Kühn-Institute, Institute for Plant Protection in Field Crops and Grassland, Braunschweig, Germany. Email: henning.nordmeyer@jki.bund.de

Received October $9^{\text {th }}, 2013$; revised November $11^{\text {th }}, 2013$; accepted December $2^{\text {nd }}, 2013$

Copyright @ 2014 Henning Nordmeyer, Tobias Koch. This is an open access article distributed under the Creative Commons Attribution License, which permits unrestricted use, distribution, and reproduction in any medium, provided the original work is properly cited. In accordance of the Creative Commons Attribution License all Copyrights (C) 2014 are reserved for SCIRP and the owner of the intellectual property Henning Nordmeyer, Tobias Koch. All Copyright @ 2014 are guarded by law and by SCIRP as a guardian.

\section{ABSTRACT}

In the present study, the herbicidal effects of two fungicides with the active ingredients expoxiconazole, fluxapyroxad, pyraclostrobin and fenpropimorph on the two arable weeds Lamium purpureum $\mathrm{L}$. and Chenopodium album $\mathrm{L}$. were investigated. The experiments were conducted in a climate chamber under defined conditions. Sowing pods were prepared and plants at the cotyledon leaf stage were pricked out in test pods. Fungicides were applied at six application rates: $0 \%, 12.5 \%, 25 \%, 50 \%, 100 \%$ and $200 \%$ of the maximum registered dose rate in Germany. Seven days after application, the first assessment was conducted, regarding growth stage, quantity of plants and visible plant damage. Fourteen days after application, the second and final assessment was conducted, regarding growth stage, quantity of plants, visible plant damage and the fresh weight of the plants. There were herbicidal effects of the fungicides, which were presumably due to the active ingredient epoxiconazole. Epoxiconazole has effects on enzymes that are dependent on cytochrome P-450 and inhibits sterol biosynthesis and probably gibberellin synthesis. By doing so, these fungicides have similar effects to plant growth regulators. Weed species showed differential sensitivities, contractions and growth inhibition and $\mathbf{E D}_{50}$-values were calculated. Notwithstanding the probably minor relevance of the present results in agricultural practice, some effects on arable weeds might result if fungicides are applied at an early growth stage in the field. In some cases, the crop-weed competition could be shifted to the benefit of the crop. Nevertheless, the results are interesting for the field of weed research and for the assessment of the ecotoxicology of fungicides.

\section{KEYWORDS}

Chenopodium album; Dose Response; Epoxiconazole; Fungicide Treatments; Lamium purpureum; Nontarget Effects; Plant Bioassay; Weed Species

\section{Introduction}

Fungicides are commonly used in agriculture and horticulture to prevent plant disease pathogens and therefore to minimise the risk of crop losses. Nonfungicidal effects of agricultural fungicides on crop plants have been reported previously, however, there are few reports of nontarget effects of fungicides on weed species. Apart from the desired protective effects, fungicides with systemic activity in plants often show plant growth regulator characteristics, with morphological changes [1]. Field observations often show that fungicides affect the development of certain dicotyledonous weed species. The plant growth regulator activity of epoxiconazole on Galium aparine was investigated [2] and stem development was reduced. The effects induced by epoxiconazole show how these compounds rapidly modify plant development after treatment. Epoxiconazole also prevented cell separation. The results indicated that epoxiconazole is a potent plant growth regulator and are consistent with the expected effects following the inhibition of cytochrome P-450-dependent enzyme activity. Systemic fungicides applied to Poa pratensis L. often cause visible alterations in plant morphology [3] because the fungicides have nontarget plant growth-regulating activity. The potential of the fungicide tridemorph in weed control was investigated by examining its influence on Holcus lanatus and Bromus sterilis [4]. Propiconazole showed growth regulator effects on redroot pigweed, Amaranthus retroflexus [5]. Experiments confirmed that pre-emergence applica- 
tions of propiconazole reduced the biomass accumulation of several common broadleaf and grass weeds by $15 \%$ to $63 \%$. Herbicidal effects of several fungicides, e.g. on Viola arvensis Murray, G. aparine L., Stellaria media (L.) Vill and Alopecurus myosuroides Huds were characterised [6]. In these studies, fungicides from the substance groups benzimidazoles, morpholines and azoles were examined and the resulting effects were species-specific and depended on the growth stage and active ingredients.

The aim of this project was to investigate the herbicidal effects on common arable weeds, of fungicides usually used on cereals. Trials with different weed species, fungicides and dose rates were carried out on Chenopodium album L. and Lamium purpureum L.

\section{Material and Methods}

\subsection{Plants}

For the experiments, two weed species were chosen to test the herbicidal effects of fungicides. The first was Lamium purpureum L.; the second was Chenopodium album L. Both these species are very common in many regions of the world. Lamium purpureum is native to the Mediterranean part of northern Africa and to Eurasia, but can be found today in many countries in Europe, North and South America and Asia [7]. Chenopodium album is currently found in many regions between latitudes $70^{\circ}$ North and $50^{\circ}$ South [8].

\subsection{Fungicides}

Adexar (BASF, Germany), one of the applied fungicides, is an emulsifiable concentrate that contains two active ingredients; epoxiconazole (62.5 g/L, 6\% w/w) and fluxapyroxad $(62.5 \mathrm{~g} / \mathrm{L}, 6 \% \mathrm{w} / \mathrm{w})$. It is a systemic fungicide for use in winter and spring wheat, durum wheat, winter and spring barley, oats, rye and triticale. Epoxiconazole belongs to the chemical class of triazoles and the group of DMI fungicides. This active ingredient inhibits sterol biosynthesis in fungi by inactivating cytochrome P-450 $14 \alpha$-demethylase [1]. Fluxapyroxad is a carboxamide of the SDHI-group, which inhibits succinate dehydrogenase in complex II of the mitochondrial respiratory chain. Thus, fluxapyroxad inhibits the germination of spores, germ tubes and mycelial growth [9].

Diamant (BASF, Germany), the other applied fungicide, is a suspo-emulsion that contains three active ingredients; expoxiconazole (42.9 g/L, 4.1\% w/w), pyraclostrobin (114.3 g/L, 11\% w/w) and fenpropimorph (214.3 $\mathrm{g} / \mathrm{L}, 20.6 \% \mathrm{w} / \mathrm{w})$. Pyraclostrobin is a protectant fungicide with curative properties for application in winter and spring wheat and barley, and oats. This active ingredient is a foliar fungicide that is not highly mobile in the plant, but systemic activities a.i. have also been observed. Py- raclostrobin belongs to the chemical class of strobilurins and the group of QoIs and inhibits electron transport in the cytochrome bc1 complex in the mitochondrial respiratory chain and thereby the germination of spores, sporulation and mycelium growth [10]. Fenpropimorph is a systemic compound belonging to the chemical class of morpholine fungicides and its mode of action is the inhibition of ergosterol biosynthesis [11].

\subsection{Experimentation}

The experiments were carried out using two fungicides with six application rates each. The seeds were sown in potting compost under greenhouse conditions and the soil was kept moist. For L. purpureum plants, three different sowing dates were used and three seedlings with emerged cotyledons were pricked out into each pod using a dibber, with $300 \mathrm{~g}$ homogenous soil from the Julius Kühn-Institute location. For C. album, four plants at the cotyledon stage were pricked out into each pod under the same conditions as those for $L$. purpureum, but only plants of a single sowing date were used, as insufficient seedlings were obtained. These plants were cultivated in a climate chamber with $16 \mathrm{~h}$ light at temperatures from $20^{\circ} \mathrm{C}$ to $24^{\circ} \mathrm{C}$ during the day and $15^{\circ} \mathrm{C}$ to $16^{\circ} \mathrm{C}$ at night. A relative air humidity of $50 \%$ to $55 \%$ was recorded during the day and 55\% to $60 \%$ during the night. To avoid variable conditions being experienced by the different pods, the trays containing the pods were circulated three times per week in a clockwise direction on the tables in the climate chamber. All pods were labelled with the appropriate plant species, sowing date, replicate, fungicide treatment and fungicide concentration.

According to the different sowing dates, the fungicides were applied 16 (at growth stage $\mathrm{BBCH} 14$ ), 13 (at $\mathrm{BBCH} 12$ ) and 9 (at BBCH 11) days after pricking out the plants in the case of $L$. purpureum, whereas for $C$. album, the fungicides were applied 7 days (at BBCH 14) after pricking out the plants. A manually operated spraying machine was used to apply the fungicides, which had an application range of $1.5 \mathrm{~m}$ width with three nozzles (size 025, $0.9 \mathrm{~L} / \mathrm{min}$ each, pressure $2.4 \mathrm{bar}$ ) and was driven at a speed of $3.6 \mathrm{~km} / \mathrm{h}$. Adexar was sprayed at an application rate of $2 \mathrm{~L} / \mathrm{ha}(100 \%)$ and Diamant at an application rate of $1.75 \mathrm{~L} / \mathrm{ha}(100 \%)$. The experiments were carried out with four replications, using six application rates each $(0 \%, 12.5 \%, 25 \%, 50 \%, 100 \%$ or $200 \%)$.

After application, the pods were kept in a greenhouse, to allow the fungicide to dry on the plant surface. For both plant species, two assessments were conducted; the first was carried out one week after application regarding growth stage, quantity of plants and visible plant damage and the second was performed two weeks after application regarding the same parameters and also the fresh weight of the plants for each pod. The growth stage 
$(\mathrm{BBCH})$ was determined using the extended BBCH-scale [12], whereas the degree of plant damage was assessed with the naked eye.

\subsection{Statistical Analysis}

The data sets were analysed for normal distribution using the Kolmogorow-Smirnow-test and subsequently tested using one-way ANOVA and the Duncan-test for significant differences $(p<0.05)$. Analyses were conducted with IBM SPSS Statistics 19. Dose-response-curves as well as the effective dose ( $\mathrm{ED}_{10}, \mathrm{ED}_{50}$ and $\mathrm{ED}_{90}$ values) were conducted using the statistical program $\mathrm{R}$ version 2.15.2 [13].

\section{Results}

\subsection{Symptoms}

In the first assessment, L. purpureum plants showed diverse symptoms. After Adexar application 16 days after pricking out the plants (sowing date 1, Table 1), they showed a leaf discoloration at almost all fungicide concentrations and sowing dates, even in the control treatment at $0 \%$ fungicide concentration. At $12.5 \%$ application, some black point necroses were visible, at $25 \%$ application some lower leaves were slightly stained brownish and in the 50\% treatment, some of the middle leaves were also stained brownish. Almost all plants occasionally showed necrotic leaf margins and leaves. Some shoots were elongated and in BBCH 51 to 55 at concentrations between $12.5 \%$ and $200 \%$. All other plants treated with Adexar 16, 13 or 9 days after pricking out were in BBCH 22 to 24. Very few necroses and point necroses and a partial brightening of the control plants were visible on plants that were treated 13 days after pricking out. More necroses and chloroses on the leaves and leaf margins of plants of this sowing date were observed, together with an increase in the fungicide concentration. At a concentration of $200 \%$, some plants showed atrophied secondary shoots. On the third sowing date (9 days after pricking out) all plants displayed partial necroses and chloroses on the leaves and leaf margins. In the 50\% treatment, some plants showed atrophied secondary shoots; and in $100 \%$ and $200 \%$ treatments, even more secondary shoots were atrophied and some leaves were darker, and showed leaf deformations and frequent necroses and chloroses.

In the case of Diamant application, all plants had reached $\mathrm{BBCH} 22$ to 24, except for some plants from the first sowing date, which showed elongated shoots at BBCH 51 to 61 at the first assessment, at 7 DAT. Most plants showed a brightening of the leaves, partial chloroses and necroses and at higher concentrations (100\% and $200 \%$ ), some darker leaves with deformations. There were no major differences between the plants from dif-
Table 1. Herbicidal effects of Adexar (2 L/ha) on Lamium purpureum (first assessment, at 7 days after treatment (DAT)) with different concentrations and sowing dates $(1=16$ days (application at BBCH 14), 2 = 13 days (application at BBCH 12) and 3 = 9 days (application at BBCH 11) after pricking out the plants). Assessment at BBCH 22 - 24.

\begin{tabular}{c}
$\begin{array}{c}\text { Sowing } \\
\text { date }\end{array}$ \\
\hline 0\%: brightening of leaves, leaf margins occasionally necrotic \\
12.5\%: brightening of leaves, leaf margins and leaves \\
occasionally necrotic, partially black point necroses, one \\
shoot at BBCH 51
\end{tabular}

25\%: brightening of leaves, leaf margins occasionally necrotic, some lower leaves slightly stained brownish, one single shoot strongly elongated, three shoots at BBCH 51 - 55

$150 \%$ : brightening of leaves, leaf margins occasionally necrotic, some lower and a few middle leaves slightly stained brownish, three shoots at BBCH 51 - 55

100\%: brightening of leaves, leaf margins occasionally necrotic, some lower leaves slightly stained brownish, one shoot at BBCH 51

200\%: brightening of leaves, leaf margins occasionally necrotic, some lower leaves slightly stained brownish, two shoots at BBCH 51

0\%: partial brightening of leaves, very few necroses on leaf margins, occasional point necroses

12.5\%: partial brightening of leaves, few necroses on leaf margins, occasional point necroses, secondary shoots atrophied partially

2 25\%: partial necroses and chloroses on leaves and leaf margins

50\%: partial necroses and chloroses on leaves and leaf margins

$100 \%$ : brightening of leaves, occasional necroses and chloroses on leaves and leaf margins

200\%: brightening of leaves, partial necroses and chloroses on leaves and leaf margins, secondary shoots partially atrophied

$0 \%$ : partial necroses and chloroses on leaves and leaf margins

12.5\%: partial necroses and chloroses on leaves and leaf margins

25\%: occasional brightening of leaves, partial necroses and chloroses on leaves and leaf margins

$50 \%$ : occasional brightening of leaves, partial necroses and 3 chloroses on leaves and leaf margins partially, secondary shoots atrophied

$100 \%$ : secondary shoots and in one plant primary shoot atrophied, deformations of the leaves, frequent necroses and chloroses on leaves and leaf margins

200\%: secondary shoots strongly atrophied, leaves coloured more dark and partially deformed, frequent necroses and chloroses

ferent sowing dates.

Plants of C. album had reached growth stage 16 to 22 in the case of Adexar and Diamant treatment at the first assessment at 7 DAT (Table 2). C. album plants showed diverse symptoms, according to the different fungicide concentrations, whereas the control plants only exhibited stunted growth but no further damage. An increasing 
Table 2. Herbicidal effects of Adexar and Diamant on Chenopodium album (first assessment, 7 DAT) with different concentrations applied at BBCH 14 (7 days after pricking out the plants).

\begin{tabular}{|c|c|c|}
\hline Fungicide & $\begin{array}{c}\mathrm{BBCH} \text { at } \\
\text { assessment }\end{array}$ & Symptoms at different concentrations \\
\hline \multirow{6}{*}{$\begin{array}{l}\text { Adexar } \\
2 \text { L/ha } \\
(100 \%)\end{array}$} & $16-24$ & 0\%: some plants atrophied, no further damage \\
\hline & $16-24$ & 125\%: plants smaller than controls, some deformations and partially necrotic in deformed leaf parts, partial chloroses \\
\hline & $16-24$ & $\begin{array}{c}\text { 25\%: plants smaller than } 12.5 \% \text { application, more deformations, leaves are one third to one half necrotic, } \\
\text { rarely regular grown leaves }\end{array}$ \\
\hline & $16-22$ & $\begin{array}{l}50 \% \text { : the same as } 25 \% \text { concentration, but stronger necroses, most plants strongly atrophied, } \\
\text { lower leaves partially dead, all leaves more or less deformed }\end{array}$ \\
\hline & $14-16$ & 100\%: plants hardly grown at all, many necroses and chloroses, almost all leaves deformed, lower leaves frequently dead \\
\hline & $14-16$ & $\begin{array}{l}200 \% \text { : the same as at } 100 \% \text { concentration, but plants even more atrophied and even upper } \\
\text { leaves partially dead, shoot tips strongly atrophied }\end{array}$ \\
\hline \multirow{6}{*}{$\begin{array}{c}\text { Diamant } \\
1.75 \mathrm{~L} / \mathrm{ha} \\
(100 \%)\end{array}$} & $16-24$ & 0\%: some plants small and slightly chlorotic, no further damage \\
\hline & $14-24$ & 12.5\%: plants small and partially atrophied, a few chloroses and some leaves slightly deformed \\
\hline & 16 (some 22) & 25\%: upper leaves deformed, some plants atrophied with point necroses \\
\hline & $16-22$ & 50\%: all plants small with deformed shoot tips, partial chloroses and necroses on the leaves \\
\hline & $14-24$ & 100\%: all plants strongly atrophied, almost all leaves deformed with larger necroses and chloroses \\
\hline & $14-16$ & $\begin{array}{l}\text { 200\%: all plants strongly atrophied, almost all leaves deformed with larger } \\
\text { necroses and chloroses, all shoot tips strongly atrophied }\end{array}$ \\
\hline
\end{tabular}

degree of damage was observed, together with an increase in the concentration of Adexar or Diamant. At higher concentrations, C. album plants were smaller, and had more chloroses, point necroses and deformed shoot tips. At the highest fungicide concentrations, all plants were badly atrophied, with heavily deformed shoot tips. Both Adexar and Diamant fungicides also left almost no healthy leaves at a concentration of $200 \%$ and some parts of the leaves were severely necrotic and chlorotic or dead.

In the second and final assessment at 14 DAT, necroses were found on leaf margins, as well as brightening of leaves, brownish stained lower leaves and an involution of the upper leaves slightly downwards in all plants of $L$. purpureum treated with Adexar. At higher fungicide concentrations, deformations of the leaves occurred. At the second and third sowing dates, secondary shoots that were atrophied at the first assessment were partially brownish and deformed. All plants were at BBCH 32 to 34, excepting some plants from the first and second sowing dates that reached $\mathrm{BBCH} 51,55$ or 65 . In the case of Diamant application, plants of $L$. purpureum were at BBCH 31 to 34, with some exceptions of plants from the first and third sowing date. Similar to Adexar application, plants showed necroses on leaves and leaf margins, brightening of the leaves (less in the control and $12.5 \%$ treatment) and a downwards partial involution of the upper leaves. Again, secondary shoots that were atrophied at the first assessment were now partially brownish and deformed. Deformations of the leaves were more frequent at higher fungicide concentrations.

In the test series with $C$. album, plants showed the symptoms explained in the first assessment after Adexar or Diamant application, but symptoms were more pro- nounced. In both fungicide test series, plants were in different growth stages; at higher fungicide concentrations, most of them were much less developed.

\subsection{Fresh Weight and Fungicide Concentration}

In the case of Adexar and Diamant application to $L$. purpureum, the plants showed no significantly different reaction to the changing fungicide concentrations at 14 DAT. However, C. album plants responded differently to applications of Adexar at various concentrations. In the controls, $12.5 \%$ and $25 \%$, plants showed no significantly different fresh weight to each other, but these three groups had a significantly different fresh weight compared to the $50 \%$ treatment and to the $100 \%$ and $200 \%$ concentrations, which both caused significant differences compared to the $50 \%$ treatment (Figure 1). Plants of $C$. album showed similar reactions to Diamant at 14 DAT (Figure 2).

The fresh weight of plants in the first four applications from $0 \%$ to $50 \%$ did not differ significantly, but was significantly different to that of plants treated with $200 \%$ fungicide concentration. Plants in the $100 \%$ treatment neither showed significant differences in fresh weight to plants in the first four concentration nor to those in the $200 \%$ treatment. The response of C. album plants to application of Adexar and Diamant is also illustrated in Figures 3 and 4. From the dose-response curves, EDvalues were calculated (Table 3 ), which showed that $C$. album is more sensitive to Adexar than Diamant. To reach the $50 \%$ damage concentration $\left(\mathrm{ED}_{50}\right)$, a dose rate of $44 \%$ was necessary, but for Diamant, a dose rate of $100.6 \%$ was necessary. The ED-values for $L$. purpureum could not be calculated. 


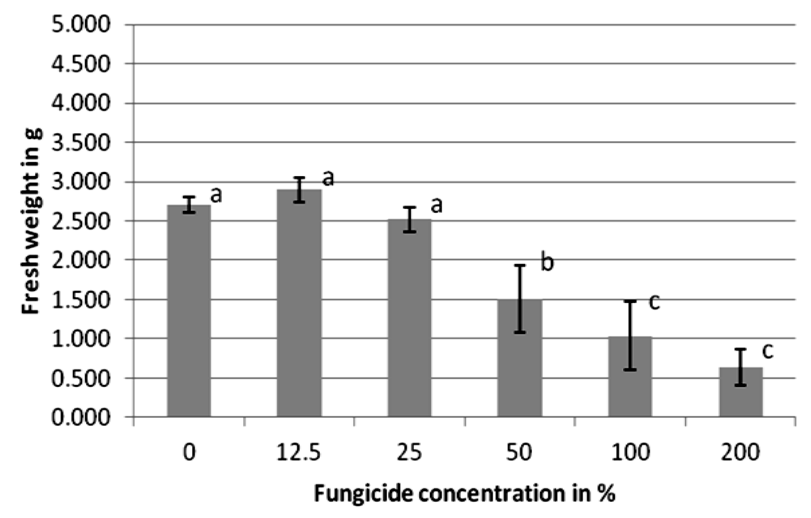

Figure 1. Herbicidal effects of different concentrations of Adexar on Chenopodium album (second assessment, 14 DAT). Columns with different letters are significantly different, according to one-way ANOVA and the Duncan-test, $p=0.0001$.

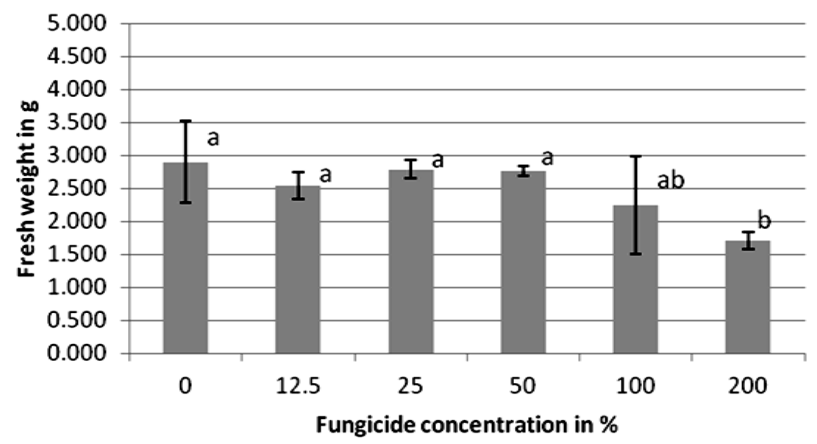

Figure 2. Herbicidal effects of different concentrations of Diamant on Chenopodium album (second assessment, 14 DAT). Columns with different letters are significantly different, according to one-way ANOVA and the Duncan-test, $p=0.006$.

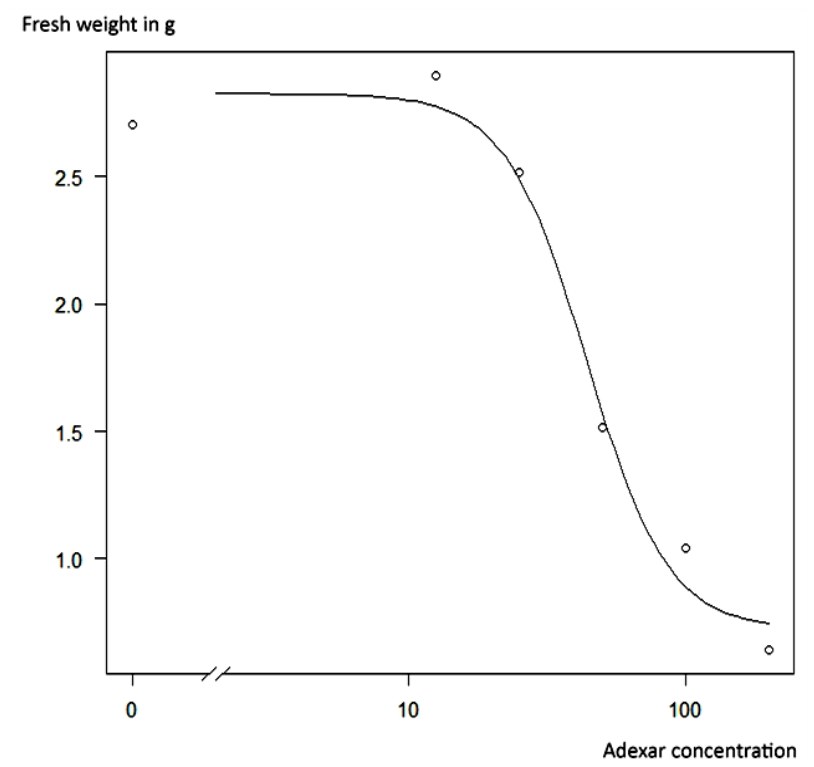

Figure 3. Dose-response-curve (14 DAT) of Adexar applied to Chenopodium album.

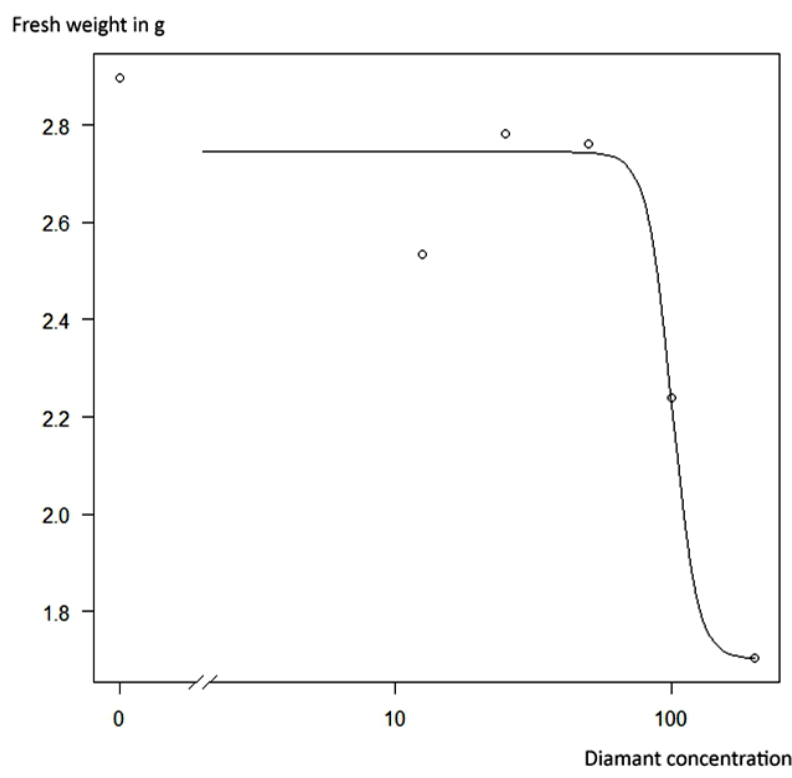

Figure 4. Dose-response-curve (14 DAT) of Diamant applied to Chenopodium album.

Table 3. Effective dose of Adexar and Diamant applied to Chenopodium album - calculated ED values (dose rate).

\begin{tabular}{ccc}
\hline ED values & Adexar & Diamant \\
\hline ED $_{10}$ & 20.9 & 80.0 \\
ED $_{50}$ & 44.0 & 100.6 \\
ED $_{90}$ & 92.5 & 126.6 \\
\hline
\end{tabular}

\subsection{Fresh Weight in Relation to Sowing Date and Fungicide Concentration}

The fresh weight of L. purpureum and C. album plants in relation to the application rate of Adexar and Diamant and to the sowing date was also investigated. Following Adexar application, the $0 \%, 12.5 \%$ and $50 \%$ treatments of $L$. purpureum showed no relationship between sowing date and fresh weight of plants at 14 DAT. In contrast, the $25 \%, 100 \%$ and $200 \%$ treatments showed significant differences between the sowing dates. At 25\% and 200\%, plants from the first sowing date had a significantly different fresh weight than those of the second and third sowing dates. At 100\% fungicide concentration, plants of the third sowing date had a significantly different fresh weight than plants of the first and second sowing dates. Following Diamant application, only the $0 \%$ treatment of L. purpureum showed no significant difference between the sowing dates at 14 DAT. At all other fungicide concentrations, the plants showed significant differences between the first sowing date and the second and third sowing dates (Figure 5).

\section{Discussion}

In most cases, the symptoms of $L$. purpureum and $C$. 


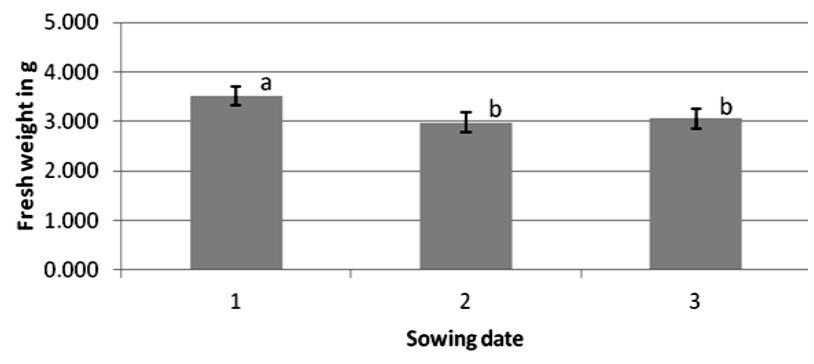

Figure 5. Herbicidal effects of Diamant on Lamium purpureum (second assessment, 14 days after treatment) at different sowing dates $(1=16$ days (application at growth stage BBCH 14), 2 = 13 days (application at growth stage BBCH 12) and $3=9$ days (application at growth stage BBCH 11) after pricking out the plants) at $12.5 \%$ fungicide concentration. Columns with different letters are significantly different, according to one-way ANOVA and the Duncan-test, $\boldsymbol{p}=\mathbf{0 . 0 0 9}$.

album were more pronounced at 14 rather than 7 days after application (DAT). The symptoms described were also reported in another study [6], which characterized darker leaves, leaf necroses and leaf deformations on several dicotyledonous weeds such as $V$. arvensis and $G$. aparine following application of diverse wheat fungicides. For $L$. purpureum and C. album, symptoms such as necroses, chloroses and leaf deformations were increasingly apparent at higher concentrations of both Adexar and Diamant fungicides. However, for L. purpureum, plants treated with the respective fungicides at all three sowing dates showed no significant difference in plant fresh weight at 14 DAT. This might be due to a thickening of the darker and deformed leaves. This was also shown by others [2] who demonstrated that application of epoxiconazole to G. aparine led not only to a reduced leaflet area, but also to an increased leaf thickness. This increase in leaf thickness was apparently due to an increased number of palisade mesophyll cells that caused a decrease in intercellular air spaces and thus, to a thickening of the leaf. Another reason for an increased leaf thickness is the elongation of cell types within the leaves. It was also shown that epoxiconazole inhibits stem elongation [2]. The authors revealed that simultaneous application of $\mathrm{GA}_{3}$ (gibberellic acid or gibberellin A3) can reduce the negative effect on stem elongation by the activity of epoxiconazole. By this approach, it was shown that the growth-retarding effects of epoxiconazole on $G$. aparine are probably due to the inhibition of enzymes that are dependent on cytochrome P-450 [2]. Gibberellins are synthesised by different enzyme classes [14], one of which contains the cytochrome P-450s, which are important for several oxidation steps in the gibberellin synthesis pathway. Thus, epoxiconazole probably inhibits cytochrome P-450-dependent enzymes and thus prevents gibberellin biosynthesis. Gibberellin A3 is a plant hormone that is responsible for promoting growth and cell elongation. Common plant growth regulators such as CCC (chlormequat chloride) also inhibit sterol biosynthesis as well as gibberellin biosynthesis [15]. Thus, epoxiconazole is an active ingredient that inhibits sterol biosynthesis and causes similar effects to plant growth regulators. In addition to epoxiconazole, most DMI-fungicides cause a plant growth retardation caused by the inhibition of sterol and gibberellin biosynthesis. The target site of these DMI-fungicides and the plant growth regulators is the oxidation of ent-kaurene. This reaction is catalysed by a cytochrome P-450 oxygenase, as well as by sterol demethylation [16].

Following fungicide application to $C$. album and $L$. purpureum, visible symptoms were more pronounced at higher fungicide concentrations. However, in contrast to L. purpureum, there were significant differences in plant fresh weight at 14 DAT, following application of Adexar or Diamant to C. album. After Adexar application, differences between the various concentrations were highly significant $(p=0.0001)$, although these were not less significant $(p=0.006)$ after Diamant application. The differences in the response of the two weed species following application of Adexar or Diamant might have a morphological or chemical basis, which cannot be demonstrated in this study. Another possible reason is the different growth stage of the plants at the time of fungicide application. Plants of $L$. purpureum were either 16, 13 or 9 days old (at the first, second or third sowing date, respectively) and plants of C. album were 7 days old after pricking out from the sowing pods. The early application of fungicides with herbicidal effects causes more effective growth retardation in weeds [6] and this study reported that early fungicide application caused stronger growth retardation in V. arvensis and G. aparine. Alternatively, it was shown that late fungicide application can also promote weed growth [6]. In the present study, plants of $L$. purpureum, irrespective of treatment with Adexar or Diamant, showed no significant differences between different sowing dates in the control treatment. Even treatment with $12.5 \%$ and $50 \%$ Adexar caused no significant differences between plants at any of the three sowing dates. However, at higher concentrations of fungicides $(25 \%, 100 \%$ or $200 \%$ of Adexar, or $12.5 \%, 25 \%$, $50 \%, 100 \%$ or $200 \%$ of Diamant), significant differences were observed between $L$. purpureum plants from the first sowing date and those of the second and third sowing date. With only one exception, a significant difference between $L$. purpureum plants of the first and third sowing date was observed following Adexar applied at $200 \%$ concentration, however, no difference was observed between plants from the second sowing date and those from the first and third sowing date. These findings lead to the assumption that age is important for the herbicidal effects of fungicides on arable weeds, which was 
also shown previously [6].

It was shown that fungicides also have herbicidal effects, which is presumably due to their active ingredient epoxiconazole. Epoxiconazole affects enzymes that are dependent on cytochrome P-450s and inhibits sterol biosynthesis and probably gibberellin synthesis. Thus, these fungicides have similar effects on plant growth regulators, which also mainly inhibit gibberellin or sterol biosynthesis.

The growth-regulatory effects of fungicides such as propiconazole on the germination and early growth of weeds might contribute to integrated weed management, especially when adequate moisture ensures the presence of germinating seeds and small seedlings throughout the growing season.

In agricultural practice, fungicides have been applied from growth stage BBCH 25 and often earlier in oil seed rape. During this period, post emergence herbicides are also used for weed control. Combination effects might be apparent but have received too little attention in the past. More research activities are needed to characterise such combination effects under field conditions. Potentially, the dose of herbicides can be reduced in combination with those of fungicides under certain conditions.

\section{REFERENCES}

[1] J. M. Benton and A. H. Cobb, "The Plant Growth Regulator Activity of the Fungicides BAS 480F," Extended Summaries SCI Pesticides Group Symposium Postgraduate Research on Pesticides. Pesticide Science, Vol. 39, No. 4, 1993, pp. 357-369.

http://dx.doi.org/10.1002/ps.2780390417

[2] J. M. Benton and A. H. Cobb, "The Plant Growth Regulator Activity of the Fungicide, Epoxiconazole, on Galium aparine L. (Cleavers)," Plant Growth Regulation, Vol. 17, No. 2, 1995, pp. 149-155. http://dx.doi.org/10.1007/BF00024175

[3] R. T. Kane and R. W. Smiley, "Plant Growth Regulating Effects of Systemic Fungicides Applied to Kentucky Bluegrass,” Agronomy Journal, Vol. 75, No. 3, 1983, pp. 469473.

http://dx.doi.org/10.2134/agronj1983.0002196200750003 $\underline{0013 x}$

[4] T. A. Watt, "The Fungicide Tridemorph as a Selective Herbicide for the Control of Holcus latus in Ryegrass and of Bromus sterilis in Barley,” Weed Research, Vol. 23, 1983, pp. 267-271.

http://dx.doi.org/10.1111/j.1365-3180.1983.tb00549.x
[5] B. D. Hanson, C. A. Mallory-Smith, B. D. Brewster, L. A. Wendling and D. C. Thill, "Growth Regulator Effects of Propiconazole on Redroot Pigweed (Amaranthus retroflexus)," Weed Technology, Vol. 17, No. 4, 2003, pp. 777781. http://dx.doi.org/10.1614/WT02-162

[6] P. Niemann, “Auswirkungen von Getreidefungiziden auf Einige Ackerunkrautarten-Side-Effects of Cereal Fungicides upon Some Arable Weeds," Nachrichtenblatt des Deutschen Pflanzenschutzdienstes, Vol. 46, 1994, pp. 126133.

[7] M. S. DeFelice, "Henbit and the Deadnettles, Lamium spp. —Archangels or Demons?” Weed Technology, Vol. 19, No. 3, 2005, pp. 768-774. http://dx.doi.org/10.1614/WT-05-072.1

[8] I. J. Bassett and C. W. Crompton, "The biology of Canadian Weeds, 32. Chenopodium album L.,” Canadian Journal of Plant Science, Vol. 58, No. 4, 1978, pp. 1061-1072. http://dx.doi.org/10.4141/cjps78-161

[9] EPA, "Pesticide Fact Sheet Fluxapyroxad," United States Environmental Proctection Agency, Office of Chemical Safety and Pollution Prevention, 2012.

[10] EPA, "Pyraclostrobin Application for Extension of the Exclusive Use Data Under FIFRA 3c(1)(f)(ii) -Part 1 of 2," United States Environmental Proctection Agency, Office of Pesticide Programs, 2007.

[11] EPA, "Pesticide Fact Sheet Fenpropimorph,” United States Environmental Proctection Agency, Office of Prevention, Pesticides and Toxic Substances, 2006.

[12] M. Hess, G. Barralis, H. Bleiholder, L. Buhr, T. H. Eggers, H. Hack and R. Stauss, "Use of the Extended BBCH-Scale-General for the Description of the Growth Stages of Mono- and Dicotyledonous Weed Species," Weed Research, Vol. 37, No. 6, 1997, pp. 433-441. http://dx.doi.org/10.1046/j.1365-3180.1997.d01-70.x

[13] R Core Team, "R: A Language and Environment for Statistical Computing," R Foundation for Statistical Computing, Vienna, 2012. http://www.R-project.org/

[14] S. E. Davidson, J. B. Reid and C. A. Helliwell, "Cytochromes P450 in Gibberellin Biosynthesis,” Phytochemistry Reviews, Vol. 5, No. 2-3, 2006, pp. 405-419. http://dx.doi.org/10.1007/s11101-006-9005-5

[15] J. E. Graebe, “Gibberellin Biosynthesis and Control,” Annual Review of Plant Physiology, Vol. 38, 1987, pp. 419465. http://dx.doi.org/10.1146/annurev.pp.38.060187.002223

[16] W. Köller, "Isomers of Sterol Synthesis Inhibitors: Fungicidal Effects and Plant Growth Regulator Activities," Pesticide Science, Vol. 18, No. 2, 1987, pp. 129-147. http://dx.doi.org/10.1002/ps.2780180206 